\title{
On the value of the 'subjective' in studies of human behavior and cognition
}

\author{
Mark Goldszmidt $\cdot$ Saad Chahine $\cdot$ Sayra Cristancho $\cdot$ Chris Watling $\cdot$ Lorelei Lingard
}

Published online: 29 January 2015

(C) The Author(s) 2015. This article is published with open access at Springerlink.com

Letter in response to: What people say $\neq$ what people do

We write this letter as a response to the letter 'What people say $\neq$ what people do', in which Dr. van Merriënboer acknowledges the generic value of subjective data but argues that they are unreliable, misleading, and best combined with objective data in the study of behaviour and cognitive processes [1]. As a research group studying teaching and learning in naturalistic clinical settings, we would like to offer a rejoinder.

First, we question the dichotomous characterization of data as either subjective or objective. We argue that a spectrum, rather than a dichotomy, exists between 'subjectivity' and 'objectivity' in research data. At one end of the spectrum are the research approaches Van Merriënboer refers to that '[ask] people their opinions' using interviews, while at the other end are research approaches that attempt to purge all external human influence. Between these poles, degrees of 'subjectivity' and 'objectivity' exist. Van Merriënboer's focus on interview techniques that seek opinions belies the richness and diversity of naturalistic data collection methods, which can employ photography, critical incident interview techniques and video-recording of human experiences. Such data are not straightforwardly 'subjective': they combine, often in nuanced ways, both more subjective (influenced by human interpretation) and more objective (unfiltered representation) dimensions. Furthermore, the

All Authors have contributed equally to the design and writing of this manuscript.

M. Goldszmidt $(\bowtie) \cdot$ S. Chahine $\cdot$ S. Cristancho $\cdot$ C. Watling $\cdot$

L. Lingard

Health Sciences Addition, Room 115, Schulich School of

Medicine and Dentistry, Western University,

London ON, N6A 5C1, Canada

e-mail: mark.goldszmidt@schulich.uwo.ca most 'objective' research - such as eye tracking analyses or double-blind randomized controlled trials - has subjective dimensions: it is necessarily influenced by human interpretation, from the wording of the question asked, to the inclusion/exclusion criteria of the sampling and the selection of statistical tests [2].

Second, we respectfully disagree with Van Merriënboer's marginalization of 'subjective data' in the study of cognition and behaviour. Calls for studying cognition and behaviour outside of the laboratory [3, 4] suggest that naturalistic research generally, and interview techniques in particular [5, 6] can offer meaningful insights into cognition and behaviour. Furthermore, many techniques exist for enhancing the rigour and authenticity of interview data regarding human cognition and behaviour $[5,6]$. Interviews may be framed around clinical case presentations to elicit valuable insights into how clinicians work, [7] as in a recent study exploring faculty supervisory practices [8]. The 'guided walk' technique enriches interviews with authentic contextual details, as in a recent study of the lived experience of medical students in remote rural communities [9]. And interview protocols that incorporate workplace observations and visual methods can elicit tacit aspects of expert practice [10, 11]. Importantly, these techniques do not reduce subjectivity in the interview. Rather, they enrich interview data with more perspectives, more interpretive resources, more glimpses of the human participants' implicit and explicit understandings of their work processes.

In conclusion, we suggest putting aside the dichotomy between subjective and objective data. We advocate that medical education researchers draw from the full spectrum of approaches in the exploration of human cognition and behaviour. From our perspective, each methodology and the data it produces have something to contribute; none is intrinsically more valuable. 
Open Access This article is distributed under the terms of the Creative Commons Attribution License which permits any use, distribution, and reproduction in any medium, provided the original author(s) and the source are credited.

\section{References}

1. Van Merriënboer JJG. What people say \# what people do. Perspect Med Educ. 2015. doi:10.1007/s40037-015-0163-2.

2. Kane MT. Validating the interpretations and uses of test scores. J Educ Measure. 2013;50(1):1-73.

3. Hutchins E. Cognition in the wild. Cambridge: MIT Press; 1995.

4. Brockner J, Higgins ET. Regulatory focus theory: implications for the study of emotions at work. Organ Behav Hum Decis Process. 2001;86(1):35-66.

5. Crandall B, Klein GA, Hoffman RR. Working minds: a practitioner's guide to cognitive task analysis. Cambridge: MIT Press; 2006.

6. Ericsson KA, Simon HA. Protocol analysis: verbal reports as data. Rev. ed. Cambridge: MIT Press; 1993.

7. Johnson JC, Weller SC. Elicitation techniques for interviewing. In: Gubrium JF, Holstein JA, editors. The Sage handbook of interview research: context and method. 2nd ed. Thousand Oaks: SAGE; 2002. p. 491-514.

8. Goldszmidt M, Faden L, Dornan T, Merriënboer J, Bordage G, Lingard L. Attending physician variability: a model of four supervisory styles. Acad Med. 2015. Accepted for publication.

9. Dube TV, Schinke RJ, Strasser R, Lightfoot N. Interviewing in situ: employing the guided walk as a dynamic form of qualitative inquiry. Med Educ. 2014;48(11):1092-100.

10. King N, Bravington A, Brooks J, Hardy B, Melvin J, Wilde D. The pictor technique: a method for exploring the experience of collaborative working. Qual Health Res. 2013;23(8):1138-52.

11. Cristancho S, Bidinosti S, Lingard L, Novick R, Ott $M$, Forbes T. Seeing in different ways: introducing rich pictures in the study of expert judgment. Qual Health Res. 2014 Oct 3. doi:10.1177/1049732314553594. Epub ahead of print.
Mark Goldszmidt is associate professor, Division of General Internal Medicine, and associate director, Centre for Education Research \& Innovation, Western University, Canada. His research programme investigates how teaching teams' habitual patterns of communication impact the quality of care they provide; how the framing of patient medical problems impact the care they receive; and what physicians reason about when seeing patients.

Saad Chahine is assistant professor, Department of Medicine and Faculty of Education, and scientist, Centre for Education Research \& Innovation, Western University, Canada. His research programme investigates how clinicians and organizations meet the increasing demands of competency-based assessment in the workplace; how validity and reliability are conceptualized in workplace-based assessment; and how the social consequences of assessment influence the design and implementation of assessment and evaluation programmes.

Sayra Cristancho is assistant professor, Department of Surgery and scientist, Centre for Education Research \& Innovation, Western University, Canada. Her research programme investigates the organizational, social and personal factors that determine the evolution of complex clinical situations and their influence on clinical judgment. Towards this end, she follows Qualitative and Systems Engineering approaches to research.

Chris Watling is associate dean, Postgraduate Medical Education, and scientist, Centre for Education Research \& Innovation, Western University, Canada. His research programme investigates the factors which influence learning in the clinical environment; the role feedback plays is in shaping learning; and what the individual and social influences on learners' receptivity is to feedback.

Lorelei Lingard is professor, Department of Medicine and Faculty of Education as well as founding director and senior scientist, Centre for Education Research \& Innovation, Western University, Canada. Her research programme investigates how health care teams talk and why it matters; how team communication patterns influence patient safety; and how medical training shape the professional identity of novices. 